\title{
DESEMPOLVANDO VIEJOS LIBROS: LAS BIBLIOTECAS DIGITALES AL SERVICIO DE LA DEMOCRATIZACIÓN DE LA LECTURA
}

\author{
Miriam LÓPEZ SANTOS \\ Universidad de León \\ mlops@unileon.es
}

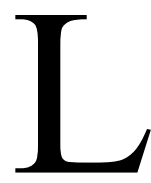

eer una pantalla no es lo mismo que leer un libro», opinaba Umberto Eco todavía en 1996. Es cierto y creo que ninguno de los aquí presentes pondrá en duda esta realidad, aunque solo acudamos a la apariencia externa y sin entrar a valorar aún ventajas e inconvenientes. Sin embargo, — apostillaba asimismo el escritor italiano - «Los libros seguirán siendo imprescindibles, para la literatura como también para cualquier circunstancia en la que uno deba leer con atención, no sólo recibir información sino también especular y reflexionar sobre ella». Quince años después de aquella afirmación tan taxativa, permitidme interrogaros directamente ¿creéis firmemente en la indispensabilidad del libro escrito y aún más en la unívoca asociación de este con la reflexión y la especulación?, ¿podemos en realidad justificar que el único cauce de la cultura sea el texto impreso? $\mathrm{O}$, dicho de otro modo, ¿es lo mismo imprescindible que primordial o no estaremos confundiendo costumbre y hábito con necesidad?; pues si así fuera tal vez la única conciliación posible pasaría porque defensores y detractores, consiguiéramos librarnos de prejuicios o aparcar por un instante aires de renovación baldíos y considerar ambas realidades en su riqueza y complejidad, e incluso complementariedad, como veremos más tarde.

Sabido es que, en ocasiones, hay veces en que las apariencias engañan y tenemos percepciones distorsionadas de las cosas. Así ha sucedido con Internet y, más específicamente, con su relación con el mundo de las Letras. En sus inicios, afirma Aguirre Romero (2005), «existía bastante recelo y parecía que el libro y el ordenador representaban espacios separados, irreconciliables, antagónicos. Ambos eran los estandartes de dos mundos: el de la fe en la tradición cultural y el de la revolución tecnológica».

Por ello quiero ante todo comenzar señalando que defiendo las bondades de ambos formatos. No consiste en una defensa a ultranza de un sistema, el digital, que presenta muchas deficiencias y carencias. Y necesito, entonces, partir de una breve reflexión sobre lo que está suponiendo en nuestras vidas la irrupción del libro digital. Es cierto, que el libro de papel es un objeto simple y muy bien 
consolidado, practico y barato. Sin duda su consumo va a disminuir pero yo apostaría por que va a sobrevivir y a convivir con las nuevas realidad electrónicas que poco a poco estarán más y más presentes que el libro tradicional. Algunos formatos, que vosotros y yo sabemos, desaparecerán con el tiempo y ya solo quedarán como resquicios de otras épocas que algunos recordaremos con nostalgia y otros como objetos de un pasado ya muy lejano que nunca llegaron a utilizar: las enciclopedias o los periódicos que no se pueden actualizar al momento, permanentemente, tienden a desaparecen más rápido. En cuanto al libro impreso, sin embargo, yo apostaría por la convivencia de lo nuevo y lo viejo. Pues los viejos editores del libro impreso pueden sin duda enseñar mucho a los nuevos del libro digital.

No debemos olvidar que el libro permitía algo adicional; había algún criterio para decidir quién puede escribir y quién no. En el mundo del libro digital eso ya no es posible, lo que es al mismo tiempo maravilloso y terrible. Cualquiera de nosotros publica día tras día sus pensamientos, sus sensaciones, sus fotos para que sean contempladas y seguidas por cientos, miles de personas, según quiénes seamos, en una explosión egocéntrica del yo que habla. Todo el mundo es yo. Todo el mundo escribe y publica y si el libro de papel no sobrevive será por sus cualidades intrínsecas, porque la cultura es lenta y nostálgica, al mismo tiempo. Es fácil hacer la prueba, preguntemos a cualquier lector, si en el viejo mundo de los libros impresos, leía dos o tres libros por semana, ahora apenas leerá uno o dos al mes, en cambio se pasará dos o tres horas al día saltando de página en página en Internet. ¿No nos pasa a todos algo parecido?

Y en mi caso, el hecho de que lean menos libros, no significa que no añore la lectura de largos libros de papel; una lectura más serena y más profundan. Decía Quevedo sobre la lectura:

\footnotetext{
Retirado en la paz de estos desiertos, con pocos, pero doctos libros juntos, vivo en conversación con los difuntos y escucho con mis ojos a los muertos.

Porque nunca dejéis de tener presente que la lectura es una conversación silenciosa y en una sola dirección con los difuntos. Comentaba Borges que Platón se inventó la forma del diálogo después de darse cuenta de que «los libros son como las figuras pintadas que parecen vivas pero no contestan una palabra a las preguntas que les hacen y Platón para atenuar o eliminar este inconveniente imaginó el diálogo filosófico». 
Sí, se trata de dos mundos en apariencia opuestos, el impreso y el digital, quizás excluyentes, piensen algunos, pero que necesitan, sin duda, caminar de la mano para sobrevivir el primero y para asentarse definitivamente y aportar credibilidad el segundo. Parto, como podéis comprobar, de la premisa de la mutua dependencia, de la necesaria interrelación. Un avance paralelo e interconectado que debe producirse desde la concienciación de la necesidad del otro para superar inconvenientes y ampliar ventajas en beneficio siempre del lector-receptor, primer y último interesado en la mejora de competencias.

La Literatura con mayúsculas no precisa de una reafirmación de su valor. Ella misma despliega su estandarte y se abre paso entre la información por muy diversa que esta sea. Sin embargo, en los últimos tiempos parece verse obligada continuamente a reclamar el sitio que le corresponde por derecho propio. Se podría afirmar que la misma necesita en cierto modo reafirmarse, y en su reafirmación, vendría atacando sin escrúpulos a un medio, el digital, que siente desde sus inicios como un enemigo que la ha herido de muerte. La literatura, no obstante, se encontraba en "peligro" mucho antes de que el libro digital entrara en nuestras vidas revolucionando la lectura, por su acceso restringido, por su tendencia a dirigirse a una élite intelectual y por acabar por asociarse casi en exclusiva a aquella, pero también y como afirma Germán Gullón (2010: 16) por su carácter «inflexible y anticuado para acoger las posibilidades comunicativas actuales». Este es el punto de partida, según mi opinión, y la realidad que esta debe asumir si pretende continuar ocupando en la sociedad el lugar que nunca debería haber abandonado: debe despojarse en fin de su tendencia elitista, de ciertas creencias del todo infundadas y abrir los ojos a la tecnología buscando un resurgimiento digno que pasa por apostar sin recelos por la democratización de la lectura.

El formato digital, por su parte, es un mundo sin fronteras pero también sin límites, sin reglas, sin clasificaciones, sin juicios de valor, y si ello, es su gran presentación al mundo también es, al propio tiempo, su condena primera. Ríos de tinta han corrido en torno a un formato que multiplica la información, que nos avasalla, nos abruma y nos dificulta la elección correcta, idónea, adecuada, aunque no excluya la dirigida. Este es uno de los principales ataques que 'los grandes hombres de letras', los anclados y aferrados a la hoja de papel y obsesionados con el canon literario, repiten sin descanso, retrotrayéndonos de nuevo a aquella 'desinformación del abuso de Información'; y puede que no les falte razón, al menos en una pequeña parte de sus argumentaciones. Pues aunque, en realidad, la era digital no ha hecho sino favorecer la adquisición y la ampliación de conocimientos al extender sobremanera la diversidad de formatos al alcance del teórico o estudioso, también la ha distorsionado, en tanto que la ha multiplicado. Requiere, entonces, y frente a la literatura, alcanzar una categoría, un estatus; afirmarse y aportar credibilidad, y ¿qué mejor aliado en esta empresa que la propia Literatura?

Las bibliotecas digitales surgieron para solventar estas deficiencias y aunar ambas realidades; análogas a bibliotecas tradicionales, se trata, como sabemos, de espacios destinados a albergar colecciones de documentos electrónicos convenientemente organizadas y dispuestas para su uso. Así, colección, organización y difusión son los tres aspectos básicos que distinguen a las bibliotecas. $\mathrm{Su}$ 
objetivo se fundamenta en formar colecciones de documentos electrónicos, organizarlas con criterios biblioteconómicos y ponerlas a disposición de los usuarios a quienes pueda interesar. Suponen, por este motivo, dentro de las posibilidades que nos aporta la tecnología, un avance casi definitivo al poner a disposición del usuario una gran cantidad de documentos y textos que favorecen y facilitan la investigación a la vez que, en términos de productividad académica, reducen las horas invertidas en el estudio y permiten análisis más completos, fiables y depurados. Miles de obras literarias que se apilaban en cientos de bibliotecas y archivos, privados o públicos, a lo largo de los cinco continentes, esperando ser leídos o hasta ser abiertos por vez primera encontraron una salida cuando la variedad de posibilidades (consulta abierta, préstamo interbibliotecario, intercambio, o facilidades de movilidad incluso) ya no resultaban suficientes. Decenas de bibliotecas, instituciones y organismos independientes, financiados, públicos o privados, llevan varios años digitalizando y catalogando muchos de sus fondos en una labor inconmensurable, impagable en aras de la cultura. Desde La Biblioteca Británica, la Biblioteca Nacional de Francia y los proyectos de la Universidad de Columbia, Virginia o Cambridge hasta las aportaciones del propio GoogleBooks, sin olvidar Europeana con el aval del informe «Nuevo Renacimiento» por citar solo alguno de ellos, suponen un conjunto en aumento que favorece el acceso libre y posibilita que millones de usuarios, investigadores, estudiosos, lectores potenciales o simples curiosos puedan aproximarse a unos libros antes desconocidos o simplemente inaccesibles.

Destacable es también la labor del Instituto Cervantes, principal difusor de nuestra lengua y nuestra cultura en el mundo. El Instituto Cervantes, con más de 40 bibliotecas físicas distribuidas a lo largo de los 5 continentes, ha puesto en marcha en su red de bibliotecas un nuevo servicio de préstamo y descarga de libros electrónicos para todos sus usuarios a través de Internet. El catálogo de libros accesible en esta plataforma incluye más de 3.000 obras sobre linguíística, obras literarias clásicas y contemporáneas de autores españoles e hispanoamericanos, historia, arte y literatura infantil. Tres son sus modalidades de lectura son las que recoge la nueva biblioteca: por un lado, la descarga libre, para publicaciones propias del Instituto Cervantes y para títulos libres de derechos de autor. En esta modalidad, el usuario se puede descargar todos los libros que desee y conservarlos en su propio dispositivo sin límite de tiempo. En segundo lugar, el préstamo, destinado a los libros sujetos a derechos de autor. Estos volúmenes, que disponen de protección anticopia con DRM, se pueden descargar en distintos dispositivos, con un plazo de préstamo de 15 días. Y por último, la lectura y visionado en streaming, para obras que se pueden leer o ver en línea, como los videocuentos. El usuario tiene también un plazo de préstamo de 15 días.

De hecho, Robert Darnton, historiador y director de las bibliotecas de Harvard, el conjunto universitario de libros mayor del mundo, se mostraba partidario, en una entrevista en 2009 (Letras Libres), de la completa digitalización de todos los libros de interés general y de poner progresivamente en línea y de manera gratuita todos los libros de aquellas colecciones para que su «contenido fuera ya de dominio público». Esta universidad, en 2006, en su convencimiento de que este era el único paso de interés hacia la instauración de lo que el propio director denominó «una república de las letras y de 
Desempolvando viejos libros: las bibliotecas digitales al servicio de la democratización...

una ciudadanía universal en el seno de esa república» ${ }^{1}$, fue una de las primeras universidades en firmar con Google un acuerdo en este sentido. Internet se convirtió gracias a estas iniciativas, en una gigantesca imprenta virtual y en una imponente librería con millones de páginas a las que poder acceder de manera instantánea.

Sin embargo, su trabajo se ha visto injustamente oscurecido al centrarse únicamente en la recuperación del texto sin entrar a valorar su contenido. El mundo digital en su pretensión de salvar la cultura y hacerla accesible al común de la sociedad olvidó vincular el aire fresco y las múltiples posibilidades del espacio digital a la excelencia del ámbito académico. Los partidarios de la digitalización se centraron en la forma y olvidaron el fondo, por lo que desde algunas esferas intransigentes se ha puesto en cuestión su credibilidad e incluso su utilidad. Habrían conseguido únicamente trasladar el concepto de biblioteca física al de biblioteca digital y, aunque no pongo ni mucho menos en duda el hecho de que las ventajas aumentan considerablemente, tampoco se han llegado a explotar al máximo las infinitas ventajas que ofrece el espacio digital más allá de la lectura horizontal, la búsqueda múltiple o el hipertexto.

Este sacrificio en favor de la Cultura ha sido devuelto en un formato que perfecciona la biblioteca digital clásica: el Portal literario. Estos nuevos espacios suponen una superación de la biblioteca digital, en tanto que siguen apostando por la tecnología pero al mismo tiempo se reafirman en la creencia de la necesidad de un proyecto serio que cuente con personas vinculadas al ámbito literario que seleccionen, discriminen, relacionen, ordenen e, incluso, para que no solo se les acuse de rancios canónicos, recuperen todo tipo de textos. Los portales literarios son, en realidad, bibliotecas digitales que emplean puentes de acceso a una o varias colecciones, secciones o grupos; organizan los contenidos y facilitan la entrada a los mismos en grados de conocimiento, de expectativas y de preparación del usuario, desde el filólogo más laureado o el estudiante que se acerca a las mismas por obligaciones académicas, al curioso que navega por Internet como mera distracción; unos y otros pueden encontrar una información acorde a sus necesidades, a su interés y a su nivel de exigencia dentro de estas plataformas y con la garantía de que no perderán excesivo tiempo en la búsqueda. Son una constatación perfecta y una prueba fehaciente de las posibilidades que puede llegar a tener el medio, si se aúnan fuerzas de diferentes profesionales: diseñadores gráficos, informáticos, ingenieros, investigadores o críticos trabajan en una misma dirección. Democratizan la lectura, es innegable, pero también la prestigian.

Podemos encontrar espacios altamente sofisticados en su presentación, sin embargo, son siempre los contenidos los que les dan su razón de ser y estos no provienen generalmente de empresas o personas dedicadas profesionalmente a la comunicación o vinculadas con el ámbito tecnológico. Por

\footnotetext{
${ }^{1}$ Armañanzas (2010: 8) desarrolla esta idea: «Las bibliotecas se van sumando a la nueva etapa de lectura digital que estamos viviendo. Además de digitalizar sus fondos, ofrecen información y servicios sobre los mismos vía digital. De esta manera, los lectores tienen acceso, a través de la red, a las grandes bibliotecas del mundo y pueden recorrer los ficheros electrónicos de millones de libros y encontrar esos ejemplares agotados y descatalogados que necesitamos. Es posible consultar catálogos completos de bibliotecas (también de editoriales) y leer en su integridad cientos de revistas de ciencia, negocios, artes, que se encuentran completamente digitalizadas en bancos de datos».
} 
lo general, suelen ser las instituciones académicas y en algunas ocasiones hasta estudiosos anónimos los que se encargarán de clasificar, de recomendar, de señalizar el material que por ella circula en beneficio de los usuarios.

Aunque han existido varios intentos dentro de nuestras letras y diversa naturaleza - divulgación, para especialistas o simplemente para satisfacer una devoción-, como El aleph, El poder de la palabra, El dígoras o El recreo, entre otros, ha sido la Biblioteca Virtual Miguel de Cervantes, al contar con el aval de grandes instituciones —especialmente la Universidad de Alicante y el Banco Santander, sus fundadores - la que ha dado un verdadero salto cualitativo; no solo ha catalogado y agrupado las obras por secciones, sino que ha dispuesto del apoyo de grandes estudiosos y teóricos responsables de su organización y seguimiento, lo que en poco tiempo la ha encumbrado como un referente básico para el acceso digital a la cultura española. Se trata indudablemente de un proyecto abierto que cuenta en la actualidad con unas 30.000 obras del patrimonio bibliográfico español y latinoamericano, y que ha ido evolucionando desde su fundación como biblioteca digital clásica, con almacenamientos arbitrarios y digitalizaciones de libros impresos, hasta el formato actual que apuesta por el portal literario y la difusión de obras cuya existencia está ligada al ciberespacio: hipernovelas, novelas multimedia, webnovelas, blognovelas, novelas colectivas o wikinovelas; esta evolución favorece que convivan ambos formatos: el acceso al catálogo mediante un formulario de búsqueda y a través de los índices de autores, géneros, movimientos o corrientes literarias, planteamiento que ha generado varias críticas que califican las consultas de poco amables, de caóticas o de demasiado enciclopédicas. Sin embargo, la apuesta por el portal literario viene a solventar estas deficiencias, que no son sino las que posee toda biblioteca digital al uso, como ya he comentado.

Frente a los portales literarios de autor, creados por aficionados, e interesantes desde el puntos de vista de la recepción y la sociología del hecho literario, y los favorecidos por las editoriales con fines específicamente publicitarios, los que ofrece la Biblioteca Virtual Miguel de Cervantes atienden especialmente necesidades académicas, en sus múltiples variedades y niveles. De autor, temáticos (géneros, grupos, corrientes o movimientos literarios) y de obras maestras o de culto, los portales que encontramos en el catálogo de la Cervantes Virtual se crean siguiendo unas pautas fijas de las que depende directamente el éxito y la utilidad del mismo. Los directores de la fundación van proponiendo temas o autores y se van completando etapas más o menos decididas de antemano: se establece un equipo, formado por un director del taller digital, encargado de los aspectos tecnológicos, del procesamiento de datos y de la presentación web, y un director académico, responsable de la catalogación y de dotar al portal de información especializada, que salvo excepciones suele ser un doctor especialista en la materia y docente; se plantea el proyecto y se realiza una memoria de los asuntos a tratar; se establecen unos plazos y el portal va tomando forma, hasta inaugurarse una vez que se inserta el grueso de la información, pero dicho portal no se cerrará, pues se irá completando el catálogo con las obras digitalizadas a medida que se localicen las mismas, las bibliotecas cedan sus fondos, los diferentes especialistas presten sus artículos, se consigan los permisos necesarios o se 
superen las trabas burocráticas, que normalmente tienen que ver con los derechos de autor, por lo que el carácter esencial del portal es el de mantenerse siempre abierto.

De la misma manera, todos presentan una disposición semejante para que el usuario se familiarice con la estructura y acceda con mayor rapidez a los contenidos que necesita. Los textos ya no aparecerán únicamente vinculados unos a los otros en torno a un tema o un autor, y ahí reside la riqueza de estos formatos; cobran más sentido en la «interactividad y en la intención de enmarcar la obra y su lengua en el contexto social en que nace, una intención verbal además de sígnica, de imágenes y sonora» (Gullón, 2010: 110). Tras un acercamiento primero, poco a poco junto a los textos, el autor empieza a emerger en la pantalla. Gracias a los enlaces sucesivos llegaremos a saber con quién se comunicaba, qué autores leía, cómo era la sociedad de su época, la música o la pintura de la misma. En efecto, los libros digitalizados aparecen catalogados, según el portal, por fechas, etapas, movimientos, con sus indicaciones pertinentes de la procedencia de la obra impresa, aunque lo verdaderamente relevante, será el contexto en que son insertados. Con la mirada puesta en el hipertexto y en la lectura horizontal, aunque es posible igualmente la vertical, se organizan en torno a un esquema que normalmente suele abrirse con una presentación que expone el objetivo del portal; tras esta podemos acceder a una introducción en la que el director académico justifica la elección del tema o autor y su relevancia en el mundo de las letras hispanas, al tiempo que se comentan aspectos históricos, o de género, novedosos o canónicos, vinculados a estos contenidos, pero siempre a través de un lenguaje accesible a los usuarios potenciales a los que irá dirigido. Junto a los conceptos teóricos, se abren nuevas ventanas con contenidos multimedia como imágenes, o materiales sonoros, para acabar completándose con la parte más novedosa del portal, la que configuran el apartado bibliográfico específico y, sobre todo, lo que se denomina «Estudios», que reconcilia la tecnología con la investigación, al ser la tarea básica de esta identificar la literatura relevante y construir un nuevo conocimiento a partir de ella. Dichos estudios son un conjunto de enlaces a artículos y libros especializados, digitalizados, que amplían considerablemente la información y que cuentan con el aval del especialista, que ha cedido de manera altruista sus investigaciones para crear un espacio de enriquecimiento, de circulación textual, de estudios accesibles y actualizados que garantizan la calidad del portal, lo que Van Harmelen ha denominado «Web semántica»: un lugar donde la investigación se realiza en la propia Red. Si se apostara más firmemente por este formato, los conocimientos ya no resultarían obsoletos, puesto que no se retrasarían las publicaciones años y años. Toda esta estructura se basa en la idea de aportar datos y crear enlaces con saberes próximos, persiguiendo líneas de información variadas a la par que uniformes. La palabra clave aquí es, como ha señalado Germán Gullón (2010: 102) «flexibilidad de acceso al saber acumulado». La llegada del «nosotros» no supone la usurpación del «yo autor» por parte del lector, sino la colaboración en la creación del sentido total. Cada usuario podrá encontrar la información que mejor se adapte a sus intereses y darle luego un sentido propio.

Aunque los de autor suelen ser los más comunes, nos interesa destacar la labor de ciertos portales temáticos que se acercan a aspectos desconocidos o poco estudiados y que resultan especialmente 
útiles por abrir el camino a la lectura de textos descatalogados, primeras ediciones o manuscritos que, de otro modo, resultarían prácticamente inaccesibles, por encontrarse en bibliotecas o archivos menores o de acceso restringido. Sus usuarios habituales son escasos, debido a sus condiciones de conservación y a la propia dificultad de comprender su naturaleza. No obstante, su interés potencial afecta a todos los ciudadanos, por su valor artístico o la pura curiosidad que producen. Sólo a partir de su digitalización asumen una identidad propia en el nuevo mundo virtual que ha aparecido con Internet. Por ello, puede afirmarse que estos portales digitales aumentan exponencialmente la cantidad de usuarios reales y potenciales. Los perfiles de cada grupo identificado determinarán la eficiencia o no de su implementación. Uno de estos ejemplos es el Portal Novela gótica el cual ofrece una serie de obras que subsisten inéditas en bibliotecas privadas o menores y facilitan la labor del investigador que puede disponer de dichos textos con mayor rapidez, realizar búsquedas más complejas dentro de los mismos, seleccionar fragmentos o ampliar conocimientos con los estudios bibliográficos; pero, al propio tiempo, reconcilia al gran público con el origen de un género, en boga en la actualidad, con millones de seguidores en todo el mundo.

Se trata, pues, de servicios de valor añadido, más cercanos a la investigación y muy especializados, pero que no son únicamente útiles a los especialistas, sino que también contribuyen a acercar la cultura a una comunidad más amplia a través de la comprensión de los textos. De hecho, no debemos olvidar en ningún momento que las exigencias de los usuarios suelen ir por delante de la oferta comercial. Sin embargo, la digitalización no solo beneficia y contribuye a mejorar la labor investigadora sino que viene asociada a una democratización de la lectura, en tanto que queda abierta a un público heterogéneo, con gustos diversos e intereses variados. Desde el mismo momento en que estas obras entran a formar parte del enorme mundo digital, el texto se reencuentra con lectores que, frente a intereses académicos, pretenden satisfacer necesidades estéticas o bien están guiados por una acuciante curiosidad. Por ello, estos portales, más que testimoniar la riqueza bibliográfica e ilustrar las posibilidades del servicio bibliotecario, prestigian, popularizan y universalizan la lectura, situando los textos al alcance del investigador, del curioso o del estudiante.

A la democratización de la lectura han contribuido igualmente los portales educativos que suministran recursos textuales y multimedia, estándares, índices y contenidos curriculares, adaptados a los diferentes niveles de enseñanza y que suelen resultar especialmente útiles para estudiantes y profesorado. Aunque se emplean con relativa normalidad en las muchas de universidades las americanas, en España, salvando las excepciones de secundaria y primaria, aún falta tiempo quizás para que se implanten y se generalicen a un nivel de enseñanza superior, si exceptuamos los estudios semipresenciales u online, por la escasez de recursos y la reticencia de un sector del profesorado ${ }^{2}$. Sin

\footnotetext{
${ }^{2}$ Son el primer paso para el desarrollo del eBook en el campo de la educación, lo que se ha denominado eText, que al pertenecer al ámbito academicista abarca más campos y no ya solo el literario, también el técnico o especializado (el jurídico goza, por ejemplo de gran aceptación). De hecho, la lectura informativa y formativa va a representar un importante porcentaje del eBook para todos los niveles educativos, desde primaria a la universidad, un ámbito especialmente útil para las editoriales que se están preparando pues supondrá en los próximos años el grueso del mercado de la edición en versión digital.
} 
embargo sería esta una medida coherente y vanguardista a tener presente en el futuro, ya que profesor y estudiante acuden con relativa normalidad a la vía electrónica para obtener gran parte de la información necesaria vinculada al ámbito académico y administrativo, dentro de la propia universidad (y ya no solo hablo de la lectura o consulta de artículos, diccionarios, enciclopedias o informes, sino de las diversas aplicaciones que hoy en día ofrecen las universidades, plataformas virtuales con toda la información sobre el desarrollo de las asignatura, como moodle o aula virtual, el correo electrónico, la consulta de las notas y hasta la propia matrícula) resulta en gran medida, lógico que el usuario se mantenga en esa vía para la búsqueda y consulta de libros e, incluso, para la lectura de los mismos, o al menos, para una parte de esa lectura.

La lógica, sin embargo, necesita que, para que resulte factible y sobre todo útil se apoye esta pretensión en una serie de ventajas y que estas superen, con creces los inconvenientes, no debemos olvidar que en el terreno en el que nos movemos suelen ser abundantes. Con estos portales, de un lado, se evitaría el derroche de papel que supone la impresión y reimpresión de muchas obras especialmente la destrucción de fondos que realizan las editoriales con los ejemplares en papel no vendidos, fruto de una necesaria renovación continua de material y de un almacenamiento demasiado costoso. Otro beneficio, junto a este, sería la rapidez con que las librerías y editoriales servirían sus fondos lo que favorecería la obtención inmediata por parte de todos los alumnos. Sin dejar al margen el hecho de que se reduciría considerablemente el peso de los libros con el que cargan, en general, los discentes, al tiempo que aumentaría la oportunidad de leer más, ya que podríamos transportar infinitos títulos y tener acceso a los mismos en cualquier momento del día o de la noche, desapareciendo la excusa de la biblioteca cerrada. Además, cuando se alcancen las prestaciones deseadas del eReader, la ampliación o reelaboración de contenidos resultaría más accesible, económica — la generalización favorece la reducción de costes - e inmediata, pues las editoriales la ofertarían como una mera actualización al libro adquirido con anterioridad y no como una nueva adquisición.

A pesar de que los beneficios resultan fácilmente constatables, de que algunos países ya empiezan a disfrutar de los mismos, y de que, como opina Pérez Tornero (2010), «En el campo de la educación, este es un camino insoslayable, ineludible», pues la lectura adquiriría un nivel de democratización más elevado, España todavía tiene un largo camino por recorrer en cuanto a la informatización de la educación ${ }^{3}$, por lo que estas propuestas continúan perteneciendo casi al ámbito

El libro de texto en formato electrónico será, según han vislumbrado estudiosos como Cabero, Llorente y Román (2004), «el gran salto cualitativo». Ya comienza a haber algunos proyectos, centrados especialmente en la esfera universitaria, donde los alumnos son más autónomos y suelen estar más familiarizados con los materiales digitales. A principios del año 2010, el Estado de California establecía por ley que, a partir de 2020, cualquier persona o empresa que venda libros de texto para la Universidad de California, Universidad Estatal de California o universidades privadas debe hacerlo también disponible en formato electrónico (eText) (Comunicación Cultural 2010).

${ }^{3}$ Emy Armananzas (2010) ha recogido ciertos datos al respecto que confirman lo esperable, que la extensión y el uso de las Tics en la Península se sitúa en el rango medio de los países de la Unión Europea, según un estudio que acaba de publicar el Ite (Instituto de Tecnologías Educativas), con datos de Eurostat referidos a 2008 y que recoge Pérez Tornero (2010b). El porcentaje de personas que han empleado en España el ordenador para el aprendizaje es apenas un 7,2\%, es decir, entre los más bajos de la Unión, sobre todo si se tiene en cuenta que los centros están pobremente dotados. Los proyectos para mejorar esta realidad son tímidos y se sitúan, como se ha señalado, en el ámbito de la escuela primaria y secundaria, donde el volumen de libros empleados es mucho mayor, aunque suponen un incentivo y un primer paso a la 
de la utopía; habrán de cambiar muchas actitudes para conseguirlo. Hasta entonces, la literatura continuará a la cabeza de la digitalización y los portales literarios, especialmente los que nos ofrece y prestigia la Biblioteca Virtual Miguel de Cervantes seguirán siendo uno de los espacios con más avances en este campo y que más favorezcan las necesidades lectoras, de los especialistas, de los curiosos y de los lectores obligados, si pretendemos un resurgir de la Cultura y una necesaria democratización de la misma.

Y para concluir, nuestra ilusión de poder combatir el tiempo y el olvido sigue siendo enorme, aunque nunca ni en el más perfecto de los simulacros digitales podremos reproducir todo cuanto anhelamos. Pero, no sería estupendo escuchar el Quijote en la voz de Miguel de Cervantes, ver a través de una pantalla de ordenador las peripecias diarias de Colón en el descubrimiento del nuevo mundo o asistir a la primera representación de La casa de Bernarda Alba. Todo esto es lo que permiten y sobre todo permitirán hacer cada uno de los nuevos objetos de la cultura a partir de ahora. Dijo una vez Quevedo al final de su vida: nada me desengaña, el mundo me ha hechizado. Octavio Paz puso esta frase como epílogo a uno de su libros, su poema «Espejo y agua»: «nada me desengaña, el mundo me ha hechizado», ¿a quién no hechizará este mundo fantástico, estas miles de posibilidades que se abren ante nosotros cada día? Muchos de nosotros venimos del pasado, pero vosotros sois ya el presente. Un mundo infinito de palabras que lucha por no perder la batalla ante la nada, la que provoca la falta de comunicación. Es cierto que el mundo cambia y se ha extendido el silencio; qué la lectura nos salve del vacío.

\section{Bibliografía}

Aguirre Romero, J. M. ${ }^{a}$ (1997): «Literatura en Internet ¿qué encontramos en la www?», Espéculo. Revista de estudios literarios 6, en http://www.literaturas.com/especial_literatura_en_internet_ aguirre.htm (última consulta, 1-6-2017).

- (2005): «El fluido literario: Internet y la Literatura», Espéculo. Revista de estudios literarios 31, en http://www.ucm.es/info/especulo/numero31/fluido.html (última consulta, 1-6-2017).

ARMAÑANZAS, E. (2010) «El libro electrónico, una gran herramienta para la cultura y la educación», en http://www.gabinetecomunicacionyeducacion.com/files/adjuntos/El\%20libro\%20electr\%C3 $\%$ B3nico,\%20una\%20gran\%20herramienta\%20para\%201a\%20educaci\%C3\%B3n.pdf (última consulta, 1-6-2017).

CORDÓN, J. A. (2010): «De la lectura ensimismada a la lectura colaborativa: nuevas topologías de la lectura en el entorno digital», en Polisemias visuales. Aproximaciones a la alfabetización visual en la sociedad intercultural. Salamanca, Universidad de Salamanca.

llegada del eText. La empresa Grammata y la editorial Santillana llevaron a cabo precisamente un proyecto piloto en una clase de secundaria. Se introdujo el eReader (en concreto el Papyre) que se cargaba con el contenido (lecturas, textos, lecciones) que los profesores iban a explicar a sus alumnos, especialmente en sustitución de fotocopias en papel. No es una implantación del eText, ya que los libros de texto que utilizaban los alumnos no estaban en el eReader, pero sirvió, sin embargo, como toma de contacto con las nuevas herramientas. 
GómEZ-MARTínEZ, J. L. «Hacia un nuevo paradigma: el hipertexto como faceta sociocultural de la tecnología», en http://www.ensayistas.org/critica/teoria/hipertexto/gomez/hipertexto3.htm (última consulta, 1-6-2017).

Gullón, G. (2010): El sexto sentido. La lectura en la era digital. Vigo, Editorial Academia del Hispanismo.

PÉrez TORnERO, J.M. (2010). «El libro de texto digital (1). Alfabetización mediática», en http://jmtornero.wordpress.com/2010/04/13/el-libro-de-texto-digital-i (última consulta, 1-62017).

REYES, A. (1939): «Sobre la crítica de los textos», en La experiencia literaria. México, FCE, $3^{\mathrm{a}}$ ed., 1983, pp. 160-170.

RodríGUEZ Llamas, S. (2009): «La literatura weblog en El jardín devastado de Jorge Volpi», en Revista de literatura mexicana contemporánea, $\mathrm{n}^{\mathrm{o}}$. 41, año 15, pp. 15-27. 